\title{
Overcoming restriction as a barrier to DNA transformation in Caldicellulosiruptor species results in efficient marker replacement
}

Daehwan Chung ${ }^{1,2}$, Joel Farkas ${ }^{1,2}$ and Janet Westpheling ${ }^{1,2^{*}}$

\begin{abstract}
Background: Thermophilic microorganisms have special advantages for the conversion of plant biomass to fuels and chemicals. Members of the genus Caldicellulosiruptor are the most thermophilic cellulolytic bacteria known. They have the ability to grow on a variety of non-pretreated biomass substrates at or near $\sim 80^{\circ} \mathrm{C}$ and hold promise for converting biomass to bioproducts in a single step. As for all such relatively uncharacterized organisms with desirable traits, the ability to genetically manipulate them is a prerequisite for making them useful. Metabolic engineering of pathways for product synthesis is relatively simple compared to engineering the ability to utilize non-pretreated biomass.
\end{abstract}

Results: Here we report the construction of a deletion of cbel (Cbes2438), which encodes a restriction endonuclease that is as a major barrier to DNA transformation of C. bescii. This is the first example of a targeted chromosomal deletion generated by homologous recombination in this genus and the resulting mutant, JWCB018 ( $\triangle p y r F A \triangle(C b e)$, is readily transformed by DNA isolated from E. coli without in vitro methylation. PCR amplification and sequencing suggested that this deletion left the adjacent methyltransferase (Cbes2437) intact. This was confirmed by the fact that DNA isolated from JWCB018 was protected from digestion by Cbel and Haelll. Plasmid DNA isolated from C. hydrothermalis transformants were readily transformed into C. bescii. Digestion analysis of chromosomal DNA isolated from seven Caldicellulosiruptor species by using nine different restriction endonucleases was also performed to identify the functional restriction-modification activities in this genus.

Conclusion: Deletion of the cbel gene removes a substantial barrier to routine DNA transformation and chromosomal modification of $C$. bescii. This will facilitate the functional analyses of genes as well as metabolic engineering for the production of biofuels and bioproducts from biomass. An analysis of restriction-modification activities in members of this genus suggests a way forward to eliminating restriction as a barrier to DNA transformation and efficient genetic manipulation of this important group of hyperthermophiles.

Keywords: Caldicellulosiruptor species, Biomass conversion, Restriction-modification enzymes, Cbel, M.Cbel, Targeted deletion

\section{Background}

Biomass recalcitrance represents the greatest obstacle to the efficient conversion of lignocellulosic biomass to commodity chemicals and biofuels [1-3]. For this reason, thermophilic cellulolytic bacteria that are capable of degrading and utilizing plant biomass are of special interest. Members of the Caldicellulosiruptor genus are

\footnotetext{
* Correspondence: janwest@uga.edu

${ }^{1}$ Department of Genetics, University of Georgia, Athens, GA 30602, USA

${ }^{2}$ The BioEnergy Science Center, Oak Ridge National Laboratory, Oak Ridge, TN 37831, USA
}

(c) 2013 Chung et al.; licensee BioMed Central Ltd. This is an Open Access article distributed under the terms of the Creative Commons Attribution License (http://creativecommons.org/licenses/by/2.0), which permits unrestricted use, distribution, and reproduction in any medium, provided the original work is properly cited. able to utilize several plant-derived substrates efficiently, including unpretreated switchgrass, and are the most thermophilic of the cellulolytic bacteria (optimum growth temperature near $80^{\circ} \mathrm{C}$ ) [4-6]. These species accomplish plant biomass degradation by producing an arsenal of extracellular carbohydrate degrading enzymes $[4,7,8]$ that include cellulases with multiple catalytic enzyme modules in a single multi-domain enzyme. This is distinct from, but somewhat similar to, membrane-bound cellulosomes exemplified by Clostridium thermocellum and other anaerobes [5,8-11].

\section{Biomed Central}


Recent growth experiments on crystalline cellulose (Avicel) revealed a significant disparity in plant cell wall deconstruction capability among eight sequenced Caldicellulosiruptor species [4]. These distinctive features provide a unique opportunity for the identification of enzymes that facilitate plant biomass decomposition, as well as the basis for a better understanding of the mechanisms of crystalline cellulose degradation.

The development of Caldicellulosiruptor species for "consolidated bioprocessing" (CBP) [12] has been limited by the lack of genetic tools required to create stable strains with high yields of desired biofuels and/ or bioproducts. Recently, we reported methods for efficient DNA transformation of $C$. bescii and $C$. hydrothermalis, including transformation of a shuttle vector [13] and the ability to direct marker replacement between non-replicating plasmids and chromosomal genes [14]. Restriction by CbeI was shown to be an absolute barrier to DNA transformation [15], but could be overcome by in vitro methylation of DNA by a cognate methyltransferase, M.CbeI [14].

Restriction-modification (R-M) systems were initially identified in Escherichia coli nearly 6 decades ago [16,17] and are now known to be wide spread in bacteria and archaea. Almost 90\% of bacterial genomes contain R-M systems and $43 \%$ contain four or more according to "The Restriction Enzyme Database" (REBASE) [18]. R-M systems comprise pairs of distinctive enzymatic activities, a restriction endonuclease and a DNA methyltransferase. R$M$ systems are classified as type I, type II, type IIS, type III and type IV according to enzyme composition, cofactor requirements, recognition sequence symmetry, location of DNA cleavage relative to the recognition site, and mode of action [19]. They provide the best-characterized defense mechanism in prokaryotes - a "self-nonself discrimination", against invasion of foreign DNA that includes phages or conjugative plasmids [20,21]. The methyltransferase subunits of R-M systems methylate specific sites in the host DNA ("self") thus preventing cleavage by the cognate restriction endonuclease. Nonmethylated foreign DNA ("nonself") is cleaved by the restriction endonuclease [22]. R-M systems also constitute a formidable barrier to efficient DNA transformation for genetic manipulation, especially DNA from other genera, most notably, E. coli. Eliminating restriction endonuclease activities in a number of host organisms, including Bacillus subtilis [23], Thermosynechococcus elongates [24], Borrelia burgdorferi [25], and Clostridium acetobutylicum [26], improved transformation efficiency and simplified the transformation protocols by removing the time-consuming laborious DNA modification steps.

Here we show that deletion of the gene encoding the CbeI (Cbes2438) restriction endonuclease resulted in a strain that is easily transformable with unmethylated
DNA from E. coli, eliminating the need for in vitro methylation by M.CbeI (Cbes2437). CbeI is a type II restriction endonuclease that recognizes the sequence 5'-GGCC-3' [15]. We further extend the current study to the analysis of chromosomal DNA modification in other species of Caldicellulosiruptor, showing that the pattern of DNA modification is quite diverse across the genus. Both GenBank [27] and REBASE [18] predicted that all 8 sequenced Caldicellulosiruptor species [28-33] contain a large number of R-M systems. While the isolation or construction of restriction-deficient strains for all members of this genus is impractical at this time, plasmid DNA from C. hydrothermalis, which appears to have a similar R-M system to $C$. bescii, is transformable to $C$. bescii without additional modification. We present a strategy for transformation and genetic manipulation of the other species within the Caldicellulosiruptor genus.

\section{Results and discussion}

\section{Restriction digestion analysis of chromosomal DNA from} Caldicellulosiruptor species

We previously reported that the restriction endonuclease, CbeI, presents an absolute barrier to transformation of C. bescii [15] with DNA isolated from E. coli, and this was successfully overcome by in vitro methylation of transforming DNA with M.CbeI, the cognate methyltransferase [14]. The observation that restriction was an absolute barrier to DNA transformation of C. bescii prompted us to investigate the prevalence of functional R-M systems in other Caldicellulosiruptor species. The finding that the M.CbeI methylated DNA successfully transformed C. hydrothermalis [13] suggested that $C$. hydrothermalis and $C$. bescii might share similar R-M activities. A large number of putative R-M systems with significant variation were detected in Caldicellulosiruptor species based on REBASE [18] and GenBank [27] analysis. To address the issue of which, if any, of these R-M systems are functional, chromosomal DNA was isolated from 7 Caldicellulosiruptor species and digested with each of 9 different restriction endonucleases, all of which have commercially available cognate methyltransferases (Table 1 and Additional file 1: Figure S1). We found that all species tested contain at least 3 types of functional R-M systems (Table 1). DNA isolated from each of the 7 species was resistant to digestion by BamHI and BspEI, indicating the presence of a cognate methyltransferase for these restriction endonucleases is common in this genus. Resistance to digestion by HaeIII was observed for C. bescii, $C$. hydrothermalis, C. kristjansonii, and C. saccharolyticus. Resistance to digestion by MboI was observed for C. kristjansonii, C. saccharolyticus, C. obsidiansis, C. lactoaceticus, and C. kronotskyensis. HaeIII (5'-GGCC-3') 
Table 1 Susceptibility of Caldicellulosiruptor species chromosomal DNA to restriction endonuclease digestion

\begin{tabular}{|c|c|c|c|c|c|c|c|c|c|}
\hline \multirow[t]{2}{*}{ Source } & \multicolumn{9}{|c|}{ Restriction endonucleases used for digestion } \\
\hline & Alul & BamHI & BspEI & EcoRI & Haelll & Hhal & Hpall & Mbol & Mspl \\
\hline C. bescii DSM6725 & + & - & - & + & - & + & + & + & + \\
\hline C. hydrothermalis DSM 18901 & + & - & - & + & - & + & + & + & + \\
\hline C. kristjansonii DSM12137 & + & - & - & + & - & + & + & - & + \\
\hline C. saccharolyticus DSM8903 & + & - & - & + & - & + & + & - & + \\
\hline C. obsidiansis ATCC BAA-2073 & + & - & - & + & + & + & + & - & + \\
\hline C. lactoaceticus DSM9545 & + & - & - & + & + & + & + & - & + \\
\hline C. kronotskyensis DSM12137 & + & - & - & + & + & + & - & - & - \\
\hline
\end{tabular}

"+" succeptible to digestion; "-" resistance to digestion.

and MboI (5'-GATC-3') would be expected to act as a formidable barrier for DNA transformation from $E$. coli for these species, since both enzymes are four base cutters and are known to be absolute barriers to DNA transformation in other microorganisms $[15,34,35]$. C. kronotskyensis appears to be the most different from the other species in terms of R-M systems, as it has apparent methyltransferase activity specific to HpaII and MspI recognition sites. All 7 tested species were sensitive to digestion by AluI, EcoRI, and HhaI (Table 1). In this limited test, we observed no differences between $C$. bescii and $C$. hydrothermalis and, in fact, plasmid DNA from E. coli methylated in vitro with M.CbeI readily transformed both $C$. hydrothermalis and $C$. bescii [13,14]. Both $C$. kristjansonii and $C$. saccharolyticus were very similar to $C$. bescii and C. hydrothermalis, differing only by one cognate methyltransferase activity (Table 1). This preliminary analysis with the nine enzymes tested has already provided access to genetic manipulation of $C$. hydrothermalis and while it is possible, if not likely, that other functional R-M systems exist, these data provide insight into extending genetic technologies to other members of this genus.

\section{Construction of a cbel deletion in $C$. bescii}

Transformation of DNA from E. coli to C. bescii required in vitro methylation of the DNA with M.CbeI, which was expressed and purified from E. coli, requiring a considerable amount of time and effort [14]. More importantly, the degree of methylation in vitro had a profound effect on the transformation efficiency introducing an element of variation in the method. CbeI was, therefore, an obvious first target for a chromosomal deletion in $C$. bescii. To test whether a deletion of cbeI would alleviate restriction of DNA from E. coli in C. bescii and allow transformation of unmethylated DNA, we constructed a chromosomal deletion of cbeI (Cbes2438) in JWCB005 (Figure 1A, Table 2) [13], using a targeted marker replacement strategy previously described [14]. Strain JWCB005 ( $\triangle p y r F A$, ura $^{-} /$ $5-F O A^{R}$ ) previously shown to be suitable for nutritional selection and counter-selection for 5-fluoroorotic acid (5-FOA) [13] was used as a host strain. The cbel knock-out vector, pDCW88, contains a 927 bp DNA fragment that includes both the 5' (440 bp) and 3' (487 bp) flanking regions of $c b e I$, and the wild type $p y r F$ cassette [13] for uracil prototrophic selection of transformants (Figure 1A, Additional file 1: Figure S2). This non-replicating vector in C. bescii was transformed into JWCB005 ( $\triangle p y r F A)$ with selection for uracil prototrophy followed by counterselection for 5-fluoroorotic acid (5-FOA) resistance. Initial screening of 18 isolates by PCR revealed merodiploids with a mixture of wild type and cbeI deletion genomes. Three of these were further purified on solid medium without 5-FOA and analyzed by PCR amplification of the cbel locus in the chromosome with primers DC277 and DC239 (Figure 1). PCR amplification of this locus from the parent strain JWCB005 ( $\triangle p y r F A)$ produced the expected wild type $\sim 2.4 \mathrm{~kb}$ band, while amplification from JWCB018 produced a $\sim 1.4 \mathrm{~kb}$ band indicating a deletion within this region (Figure 1B). The site of the deletion was confirmed by DNA sequence analysis of the PCR product. The resulting strain, JWCB018 ( $\Delta$ pyrFA $\Delta$ cbeI) (Table 2) was used for further analysis.

The cbeI gene is located in the chromosome adjacent to the gene encoding M.CbeI, its cognate methyltransferase $[14,15]$. The two genes are separated by only 45 bases, and are likely to be transcriptionally coupled. The deletion of cbeI spanned the entire cbeI coding region, but left the potential regulatory region upstream intact, and deleted only 23 bases of the downstream flanking region leaving the entire M.CbeI coding region intact. Chromosomal DNA isolated from JWCB018 was completely protected from cleavage by HaeIII and CbeI in vitro (data not shown), suggesting that M.CbeI is still functional in JWCB018. Growth of this mutant was comparable to growth of the parent JWCB005 and the wild type strain.

\section{The JWCB018 is efficiently transformed with unmethylated DNA}

To assess the effect of the cbeI deletion on transformation of $C$. bescii with unmethylated DNA from E. coli, 


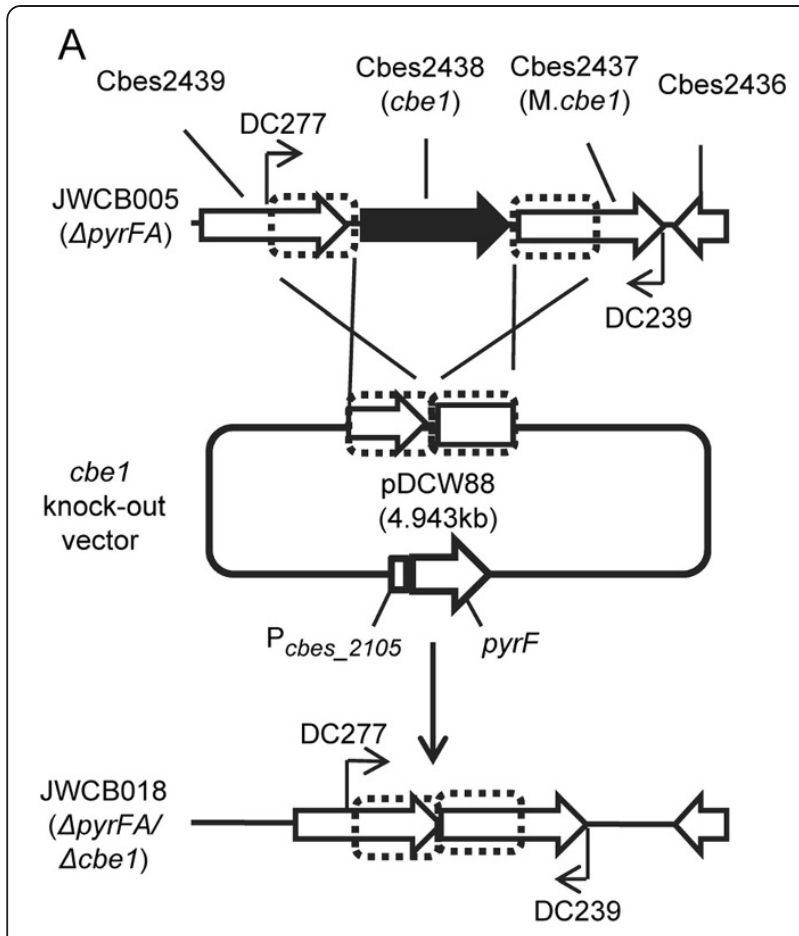

\section{B}

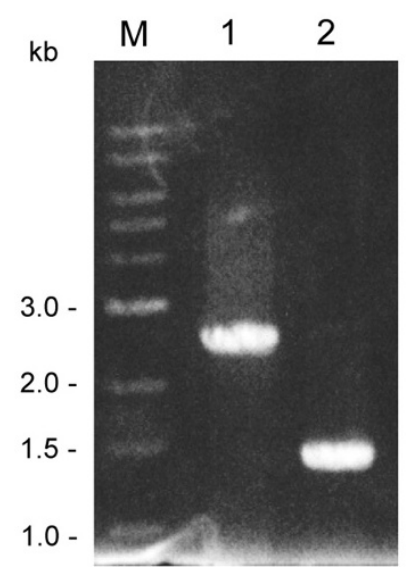

Figure 1 Strategy for construction and PCR analysis of the cbel (Cbes2438) deletion in JWCB005. (A) A diagram of the cbel genome region is shown with the cbel knock-out plasmid having $\sim 0.5 \mathrm{~kb}$ regions from each up- and downstream of cbel for homologous recombination and also containing the pyrF cassette [13] for selection of transformants. Homologous recombination can occur at the upstream or downstream cbel flanking regions, integrating the plasmid into the genome and generating a strain that is a uracil prototroph. Counter-selection with 5-fluoroorotic acid (5-FOA) selects for loss of the plasmid and deletion of the cbel gene. Bent arrows depict primers used for verification of the cbel deletion. (B) Gel depicting PCR products amplified from the cbel genome region in JWCB018 ( $\triangle p y r F A / \triangle c b e l)$ compared to the parental strain JWCB005 (ApyrFA), amplified by primers (DC277 and DC239). Lane 1: JWCB005; lane 2: JWCB018; M: 1 kb DNA ladder (NEB).

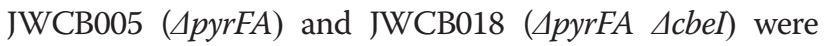
transformed with unmethylated pDCW89 DNA, using a recently developed replicating shuttle vector [13] containing a wild type copy of the $p y r F$ allele for uracil prototrophic selection (Figure 2). No transformants of the parent strain, JWCB005, were detected using unmethylated plasmid DNA isolated from $E$. coli $\left(<10^{-8}\right.$ transformants per $\mu$ g plasmid DNA). The $\Delta c b e I$ strain, however, was readily transformed with unmethylated pDCW89 DNA isolated from E. coli $\left(\sim 1.0 \times 10^{3}\right.$ transformants per $\mu \mathrm{g}$ of plasmid DNA, Figure 2A). Methylated plasmid DNA transformed into the parent strain (JWCB005) at a frequency $(\sim 0.5 \times$ $10^{3}$ transformants per mg plasmid DNA) and the difference is likely due to incomplete methylation of the plasmid DNA in vitro. Transformation of $C$. bescii was initially confirmed by PCR amplification of the pSC101 E. coli replication origin fragment present only in the plasmid (data not shown). Isolation of large quantities of pDCW89 from $C$. bescii for direct analysis proved to be difficult, likely due to low copy number as a result of competition with the endogenous plasmid, pBAS2 [13,37]. Total DNA isolated from JWCB018 transformants was used to "back-transform" E. coli and plasmid DNA isolated from these back-transformants was analyzed by restriction digestion (Figure 2B). pDCW89 DNA isolated from the "back transformants" was indistinguishable from the pDCW89 used to transform C. bescii and showed no obvious signs of rearrangement or deletion through transformation into JWCB018, replication in C. bescii or back-transformation to E. coli (Figure 2B).

\section{Plasmid DNA isolated from C. hydrothermalis readily transforms strain JWCB005 (DpyrFA) without in vitro methylation}

Given the fact that C. hydrothermalis and C. bescii showed the same observed functional R-M activities (Table 1), we anticipated that DNA isolated from $C$. hydrothermalis would be methylated by its homologue of M.CbeI (Calhy0409) and that plasmid DNA isolated from $C$. hydrothermalis might transform C. bescii without in vitro methylation. Plasmid DNA was readily isolated from $C$. hydrothermalis transformants (perhaps indicating a high copy number in C. hydrothermalis as it is derived from a high copy number $C$. bescii native plasmid [13,37]) and used to transform $C$. bescii. Transformants were obtained at frequencies comparable to M.CbeI methylated plasmid $\left(\sim 0.5 \times 10^{3}\right.$ per $\mathrm{mg}$ of plasmid DNA). The presence of pDCW89 in transformants was confirmed using PCR amplification of the aac (apramycin resistance gene), pSC101 ori region, and $p y r F$ cassette, contained only on the plasmid. The size of the PCR products obtained in this analysis were as expected and were generated from total DNA isolated from the JWCB005 transformants and plasmid DNA isolated from E.coli, but not from JWCB005 (Figure 3). Total DNA, isolated from JWCB005 transformants, was back-transformed to $E$. coli for further analysis. 
Table 2 Strains and plasmids used in this study

\begin{tabular}{|c|c|c|}
\hline Strains or plasmid & Strain and genotype/phenotype & Source \\
\hline \multicolumn{3}{|l|}{ Caldicellulosiruptor } \\
\hline C. bescii DSM6725 & Wild type / $\left(\mathrm{ura}^{+} / 5-\mathrm{FOA}^{\mathrm{S}}\right)$ & $\mathrm{DSMZ}^{1}$ \\
\hline C.hydrothermalis DSM18901 & Wild type / $\left(\mathrm{ura}^{+} / 5-\mathrm{FOA}^{\mathrm{S}}\right)$ & $\mathrm{DSM} \mathrm{Z}^{1}$ \\
\hline C. kristjansonii DSM12137 & Wild type / $\left(\mathrm{ura}^{+} / 5-\mathrm{FOA}^{\mathrm{S}}\right)$ & DSMZ \\
\hline C. saccharolyticus DSM8903 & Wild type / $\left(\right.$ ura $\left.^{+} / 5-\mathrm{FOA}^{\mathrm{S}}\right)$ & $\mathrm{DSMZ}^{1}$ \\
\hline C. obsidiansis ATCC BAA-2073 & Wild type / $\left(\mathrm{ura}^{+} / 5-\mathrm{FOA}^{\mathrm{S}}\right)$ & DSMZ \\
\hline C. lactoaceticus DSM9545 & Wild type / $\left(\mathrm{ura}^{+} / 5-\mathrm{FOA}^{\mathrm{S}}\right)$ & $\mathrm{DSM} \mathrm{Z}^{1}$ \\
\hline C. kronotskyensis DSM12137 & Wild type / $\left(\mathrm{ura}^{+} / 5-\mathrm{FOA}^{\mathrm{S}}\right)$ & DSMZ \\
\hline JWCB005 & C. bescii $\triangle p y r F A$ / (ura $\left./ 5-F O A^{R}\right)$ & [13] \\
\hline JWCB018 & C. bescii $\triangle$ pyrFAAcbel / (ura $\left.{ }^{-} / 5-\mathrm{FOA}^{\mathrm{R}}\right)$ & This study \\
\hline JWCHOO3 & C. hydrothermalis IScahyl insertion mutation in pryF gene / (ura ${ }^{-} / 5-\mathrm{FOA}^{\mathrm{R}}$ ) & {$[13,36]$} \\
\hline JWCH005 & JWCH003 transformed with M.Cbel methylated pDCW89 / (ura $\left.{ }^{+} / 5-\mathrm{FOA}^{\mathrm{S}}\right)$ & [13] \\
\hline \multicolumn{3}{|l|}{ Escherichia coli } \\
\hline JW291 & DH5a containing pDCW88 (Apramycin $\left.{ }^{R}\right)$ & This study \\
\hline JW292 & DH5a containing pDCW89 (Apramycin ${ }^{R}$ ) & [13] \\
\hline \multicolumn{3}{|l|}{ Plasmids } \\
\hline pDCW88 & cbel kcock-out vector (Apramycin ${ }^{R}$ ) & This study \\
\hline pDCW89 & E. coli/Caldicellulosiruptor species shuttle vector $\left(\right.$ Apramycin $\left.^{\mathrm{R}}\right)$ & [13] \\
\hline
\end{tabular}

${ }^{1}$ German collection of microorganisms and cell cultures.

Restriction analysis of plasmid DNA isolated from backtransformants showed that pDCW89 was structurally stable through transformation and replication in $C$. bescii (data not shown).

\section{Conclusions}

Here we report the construction of a deletion of cbeI (Cbes2438), which encodes a potent restriction endonuclease whose activity is apparently an absolute barrier to transformation of DNA from E. coli to C. bescii. We recently showed that in vitro methylation of DNA from $E$. coli with M.cbeI, a cognate methyltransferase from $C$. bescii, allowed transformation. Deletion of cbeI is the first targeted deletion in this genus and the resulting mutant, JWCB018 ( $\triangle$ pyrFA $\triangle$ cbel), is readily transformed by DNA isolated from $E$. coli without in vitro methylation. PCR amplification and sequencing suggested that this deletion left the adjacent methyltransferase (M.CbeI) intact and its function was confirmed by the fact that chromosomal DNA isolated from JWCB018 was protected from digestion by CbeI and HaeIII in vitro.

The construction of this mutant strain removes a substantial barrier to routine transformation and chromosomal modification and is substantially more efficient than other possible methods including modification of the vector prior to transformation, using engineered vectors containing no or fewer restriction sites recognized by restriction endonuclease in host $[38,39]$, conditional inactivation of the R-M systems $[40,41]$ or using group II intron insertion technology to disrupt a restriction system in Clostridum acetobutylicum [26]. The ability demonstrated here to make targeted gene deletions is a powerful and direct tool for the investigation of in vivo gene function and the deletion of this endonuclease resulted in a strain that will provide the basis for further genetic manipulation. The combined efficiencies of transformation and homologous recombination (with as few as $450 \mathrm{bp}$ of homology) in C. bescii allow us to use non-replicating plasmids for genetic manipulation. This is fortuitous and a significant benefit for the development of Caldicellulosiruptor species as CBP organisms. The proven CBP microbe, Clostridium thermocellum, for example, is genetically tractable but the efficiency of transformation and/or recombination does not permit the use of non-replicating plasmids for marker replacement, significantly extending the time required for mutant construction [42].

Plasmid DNA isolated from $C$. hydrothermalis was able to transform $C$. bescii JWCB005 ( $\triangle p y r F A)$ and $C$. bescii JWCB018 ( $\triangle p y r F A \triangle c b e I)$, however total DNA isolated from the $C$. bescii transformant did not transform C. hydrothermalis. This apparent contradiction could be due to the low concentration of pDCW89 in total DNA isolated from the $C$. bescii transformant [13]. Alternatively, this may be due to yet another unidentified R-M system difference between these species. REBASE [18] 


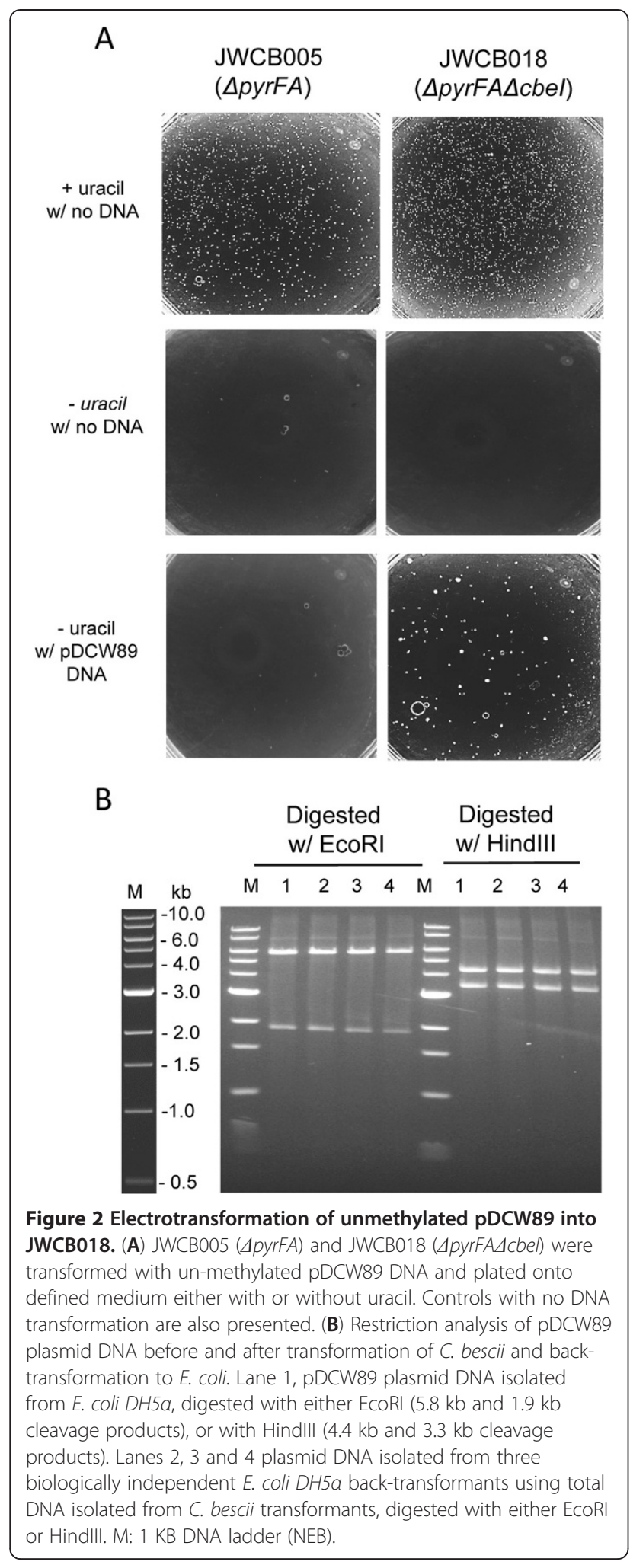

predicts that the genome of $C$. bescii encodes as many as six methyltransferases in addition to M.CbeI and that C. hydrothermalis contains as many as six restriction

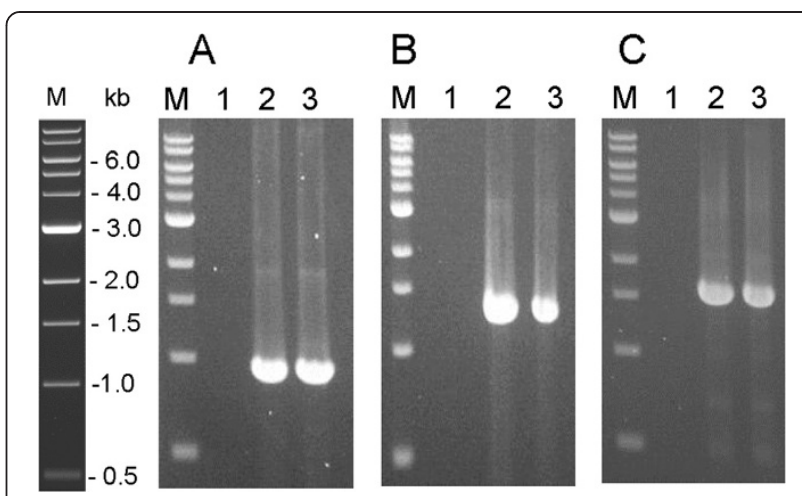

Figure 3 PCR analysis for the presence of pDCW89 after transformation into JWCB005. pDCW89 DNA isolated from C. hydrothermalis transformants was used to transform C. bescii ( $\triangle p y r F A)$ and the presence of the plasmid was confirmed by PCR amplification of sequences contained only on the plasmid (A) the $0.9 \mathrm{~kb}$ PCR product of aac (Apramycin Resistance gene cassette), (B) the $1.3 \mathrm{~kb}$ PCR product of pyrF cassette and (C) the $1.6 \mathrm{~kb}$ PCR product of $p S C 101$ ori region. Lane 1: total DNA isolated from JWCB005; lane 2: total DNA isolated from C. bescii transformant; lane 3: pDCW 89 isolated from E. coli. M: 1 kb DNA ladder (NEB).

endonucleases, one of which (Calhy0018) is a type IV (methyl-directed) restriction endonuclease not present in $C$. bescii. If this type IV restriction endonuclease is active and recognizes methylated DNA formed by a $C$. bescii methyltransferase not present in $C$. hydrothermalis, the DNA isolated directly from $C$. bescii would be cleaved. Somewhat surprisingly, the disruption of only one functional restriction enzyme was enough to overcome restriction as a barrier to transformation of $C$. bescii by $E$. coli DNA. This may be due to the fact that BamHI and BspEI are rare cutters in C. bescii genomic DNA and neither of these sites is present in pDCW88 used to make the deletion of cbeI. Only one BspEI site is present in the pDCW89 shuttle vector and that may be protected due to an overlapping dam site created by in vivo methylation in E. coli DH5 $\alpha$. It is also possible that the cognate restriction endonuclease of the BspEI methyltransferase is inactive or absent altogether.

Perhaps the most powerful conclusion to be drawn from these data is the direction forward in overcoming $\mathrm{R}-\mathrm{M}$ systems as a barrier to transformation of other Caldicellulosiruptor species. As shown in C. bescii, a 4 base cutter such as CbeI ( $5^{\prime}$-GGCC-3') is a formidable obstacle to transformation. In contrast, 6 base cutters can be easily avoided during plasmid construction (as with BamHI and BspEI here), as long as the functional $\mathrm{R}-\mathrm{M}$ system is known. Based on our findings, all Caldicellulosiruptor species show at least three DNA methyltransferase activities (Table 1), though it is not known that all modification activities are paired with a cognate restriction activity. In vitro methylation of plasmid DNA with cell-free extracts may be useful going 
forward to identify restriction activities that present obstacles to transformation. In any case, these observations emphasize that successful transformation is largely empirical. It was perhaps fortunate that $C$. bescii was the first chosen for genetic manipulation, because only one methyltransferase activity was required for efficient transformation of DNA from E. coli.

\section{Methods}

\section{Strains, media and growth conditions}

Caldicellulosiruptor and E. coli strains used in this study are listed in Table 2. All Caldicellulosiruptor species were grown anaerobically in liquid or on solid surface in either modified DSMZ 516 medium [14] or in low osmolarity defined (LOD) medium [43] with maltose as the carbon source. C. bescii, C. kristjansonii, and $C$. obsidiansis were incubated at $75^{\circ} \mathrm{C}$. C. hydrothermalis, $C$. kronotskyensis, C. lactoaceticus, and C. saccharolyticus were incubated at $68^{\circ} \mathrm{C}$. For growth of auxotrophic mutants, the defined medium contained $40 \mu \mathrm{M}$ uracil. E. coli strain DH5 $\alpha$ was used for plasmid DNA constructions and preparations. Standard techniques for $E$. coli were performed as described [44]. E. coli cells were grown in LB broth supplemented with apramycin $(50 \mu \mathrm{g} / \mathrm{mL})$ and plasmid DNA was isolated using a Qiagen Mini-prep Kit. Chromosomal DNA from Caldicellulosiruptor strains was extracted using the Quick-gDNA ${ }^{\mathrm{Tm}}$ MiniPrep (Zymo) or using the DNeasy Blood \& Tissue Kit (Qiagen) according to the manufacturer's instructions. Plasmid DNA isolation from Caldicellulosiruptor species was performed as described [15].

\section{Construction of $\mathrm{pDCW88}$}

A 927 bp DNA fragment containing the $5^{\prime}$ flanking region (440 bp) and the 3' flanking region (487 bp) of cbeI (Cbes2438) was generated by overlap extension polymerase chain reaction (OE-PCR) using primers DC265 (with KpnI site), DC266, DC267, and DC268 (with ApaLI site). All PCR reactions were performed using $p f u$ turbo (Agilent Technologies), and C. bescii genomic DNA as a template. The DNA fragments containing the apramycin resistance gene cassette, pyrF cassette, and the $E$. coli pSC101 replication origin, were amplified from $\mathrm{pDCW}$ 89 [13] using primers DC081 (with KpnI site) and DC262 (with ApaLI site). These two linear DNA fragments were digested with KpnI and ApaLI, and ligated to generate pDCW88 using Fast-link DNA Ligase kit (Epicentre Biotechnologies) according to the manufacturer's instructions. DNA sequences of the primers are shown in Additional file 1: Table S1. A diagram of pDCW88 is shown in Additional file 1: Figure S2. E. coli strain DH5 $\alpha$ cells were transformed by electroporation in a 2-mm-gap cuvette at $2.5 \mathrm{~V}$ and transformants were selected for apramycin resistance. The sequence of
pDCW88 was confirmed by Automatic sequencing (Macrogen USA, Maryland). All plasmids are available on request.

\section{Screening, purification, and sequence verification of deletion mutants}

To construct strain JWCB018, one microgram of M.CbeI methylated pDCW88 DNA was used to electrotransform JWCB005 ( $\triangle p y r F A)$ as described [14]. Cells were then plated onto solid defined medium (without uracil and casein) and uracil prototrophic transformant colonies were inoculated into liquid medium for genomic DNA extraction and subsequent PCR screening of the targeted region. Confirmed transformants were inoculated into nonselective liquid defined medium, with $40 \mu \mathrm{M}$ uracil, and incubated overnight at $75^{\circ} \mathrm{C}$ to allow loop-out of the plasmid DNA. The cultures were plated onto 5-FOA (8 mM) containing solid medium. After initial screening, transformants containing the expected deletion were further purified by three additional passages under selection on solid medium and screened a second time by PCR to check for segregation of the deleted allele. The deletions were then verified by PCR amplification and sequence analysis. A PCR product was generated from genomic DNA by using primers (DC277 and DC239) outside the homologous regions used to construct the deletion, and internal primers were used to sequence the PCR product. For PCR, the extension time was sufficient to allow amplification of the wildtype allele, if it were still present. Another set of primers, one located inside of the Cbes 2438 open reading frame, and the other located outside of the flanking region were used for further verification. Growth of this strain, JWCB018, supplemented with uracil (40 $\mu \mathrm{M})$ was comparable to wild type reaching a cell density of $\sim 2 \times 10^{8}$ in 20 hours. Cells were counted in a Petroff Hausser counting chamber using a phasecontrast microscope with $40 \mathrm{X}$ magnification.

\section{Transformation of $C$. bescii and selection of transformants} Electrotransformations of JWCB005 and JWCB018 with unmethylated pDCW89 from E. coli or isolated plasmid DNA from C. hydrothermalis transformants were performed as described [14]. For selection of transformants, after electro-pulse the recovery cultures with pDCW89 DNA $(0.5-1.0 \mu \mathrm{g})$ were plated onto the defined medium without casein and uracil. Uracil prototrophic transformants were inoculated into liquid medium for DNA isolation. The presence of plasmid sequences in $C$. bescii transformants was confirmed by PCR amplification of the aac (apramycin resistance gene cassette) gene, the $\mathrm{pSC} 101$ ori region, and the pyrF cassette, present only on pDCW89. The 
transformation frequencies reported herein take into account the number of cells plated as determined by culture cell counts (this does not take into account the plating efficiency), and, where indicated, the total amount of DNA added (i.e., the number of transformants per microgram of DNA). E. coli strain DH5 $\alpha$ cells were used for back-transformation.

\section{Restriction endonuclease digestion of Caldicellulosiruptor species chromosomal DNA}

Chromosomal DNA isolated from seven Caldicellulosiruptor species was subjected to digestion with the REs AluI, BamHI, BspEI, EcoRI, HaeIII, HhaI, HpaII, MboI, and MspI. All enzymes were from New England Biolabs. For each reaction, 1 microgram of DNA was incubated with the enzyme and appropriate buffer for 1 hour according to the manufacturer's instructions. After incubation, digestion patterns were compared by electrophoresis on a 1.0\% agarose gel.

\section{Additional file}

Additional file 1: Figure S1. Restriction endonuclease digests of chromosomal DNA isolated from Caldicellulosiruptor species. The nine restriction enzymes employed in this analysis are indicated on the top of the gel. (A) C. bescii chromosomal DNA. (B) C. saccharolyticus chromosomal DNA. M: 1 kb DNA ladder (NEB). Figure S2. Diagram of the cbel (Cbes2438) knock-out vector. The gray colored boxes indicate sequences originating from $\mathrm{C}$. bescii. Restriction sites and primers are indicated. aac, apramycin resistant gene cassette; PSC101, low copy replication origin in E. coli; repA and par, plasmid-encoded genes required for pSC101 replication and partition. Table S1. Primers used in this study.

\section{Abbreviations}

CBP: Consolidated bioprocessing; C. bescii: Caldicellulosiruptor bescil; C. hydrothermalis: Caldicellulosiruptor hydrothermalis; C. kristjansonil: Caldicellulosiruptor kristiansonii;; C. saccharolyticus: Caldicellulosiruptor saccharolyticus; C. obsidiansis: Caldicellulosiruptor obsidiansis; C. lactoaceticus: Caldicellulosiruptor lactoaceticus; C. kronotskyensis: Caldicellulosiruptor kronotskyensis; R-M: Restrictionmodification; REBASE: Restriction Enzyme Database; 5-FOA: 5-fluoroorotic acid; LOD: Low osmolarity defined; Aac: Apramycin resistance gene cassette; LB: Luria broth.

\section{Competing interests}

The authors declare that they have no competing interests.

\section{Authors' contributions}

DC designed and carried out the overall experiments, analyzed results and wrote the manuscript. JF participated in its design and coordination, carried out the restriction analysis, and drafted the manuscript. JW helped conceive of the study, participated in its design and coordination, and helped to draft and reviewed the manuscript. All authors read and approved the final manuscript.

\footnotetext{
Acknowledgements

We thank Jennifer Copeland for outstanding technical assistance, Bob Kelly and Sara Blumer-Schuette for providing the Caldicellulosiruptor species used in this study, Joe Groom and Jenna Young for critical review of the manuscript. This work was supported by The BioEnergy Science Center supported by a U.S. Department of Energy Bioenergy Research Center supported by the Office of Biological and Environmental Research in the DOE Office of Science. JF was supported in part by a predoctoral Graduate Training in Genetics grant (NIH 5T32GM007103-30) to the Genetics Department of the University of Georgia.
}

Received: 1 April 2013 Accepted: 21 May 2013

Published: 29 May 2013

\section{References}

1. Himmel ME, Ding SY, Johnson DK, Adney WS, Nimlos MR, Brady JW, Foust TD: Biomass recalcitrance: engineering plants and enzymes for biofuels production. Science 2007, 315:804-807.

2. McCann MC, Carpita NC: Designing the deconstruction of plant cell walls. Curr Opin Plant Biol 2008, 11:314-320.

3. Wilson DB: Three microbial strategies for plant cell wall degradation. Ann N Y Acad Sci 2008, 1125:289-297.

4. Blumer-Schuette SE, Giannone RJ, Zurawski JV, Ozdemir I, Ma Q, Yin Y, Xu Y, Kataeva I, Poole FL 2nd, Adams MW, et al: Caldicellulosiruptor core and pangenomes reveal determinants for noncellulosomal thermophilic deconstruction of plant biomass. J Bacterio/ 2012, 194:4015-4028.

5. Blumer-Schuette SE, Kataeva I, Westpheling J, Adams MW, Kelly RM: Extremely thermophilic microorganisms for biomass conversion: status and prospects. Curr Opin Biotechnol 2008, 19:210-217.

6. Yang SJ, Kataeva I, Hamilton-Brehm SD, Engle NL, Tschaplinski TJ, Doeppke C, Davis M, Westpheling J, Adams MW: Efficient degradation of lignocellulosic plant biomass, without pretreatment, by the thermophilic anaerobe "Anaerocellum thermophilum" DSM 6725. Appl Environ Microbiol 2009, 75:4762-4769.

7. Blumer-Schuette SE, Lewis DL, Kelly RM: Phylogenetic, microbiological, and glycoside hydrolase diversities within the extremely thermophilic, plant biomass-degrading genus Caldicellulosiruptor. Appl Environ Microbiol 2010, 76:8084-8092.

8. Dam P, Kataeva I, Yang SJ, Zhou F, Yin Y, Chou W, Poole FL 2nd, Westpheling J, Hettich R, Giannone R, et al: Insights into plant biomass conversion from the genome of the anaerobic thermophilic bacterium Caldicellulosiruptor bescii DSM 6725. Nucleic Acids Res 2011, 39:3240-3254.

9. Bayer EA, Belaich JP, Shoham Y, Lamed R: The cellulosomes: multienzyme machines for degradation of plant cell wall polysaccharides. Annu Rev Microbiol 2004, 58:521-554

10. Bayer EA, Setter E, Lamed R: Organization and distribution of the cellulosome in Clostridium thermocellum. J Bacteriol 1985, 163:552-559.

11. Gold ND, Martin VJ: Global view of the Clostridium thermocellum cellulosome revealed by quantitative proteomic analysis. J Bacteriol 2007, 189:6787-6795.

12. Lynd LR, van Zyl WH, McBride JE, Laser M: Consolidated bioprocessing of cellulosic biomass: an update. Curr Opin Biotechnol 2005, 16:577-583.

13. Chung D, Cha M, Farkas J, Westpheling J: Construction of a stable replicating shuttle vector for caldicellulosiruptor species: Use for extending genetic methodologies to other members of this Genus 2013. PLoS One 2013, 8:e62881.

14. Chung D, Farkas J, Huddleston JR, Olivar E, Westpheling J: Methylation by a unique a-class N4-cytosine methyltransferase is required for DNA transformation of <italic>caldicellulosiruptor bescii</italic> DSM6725. PLoS One 2012, 7:e43844.

15. Chung DH, Huddleston JR, Farkas J, Westpheling J: Identification and characterization of Cbel, a novel thermostable restriction enzyme from Caldicellulosiruptor bescii DSM 6725 and a member of a new subfamily of Haelll-like enzymes. I Ind Microbiol Biotechnol 2011, 38:1867-1877.

16. Bertani $\mathrm{G}$, Weigle JJ: Host controlled variation in bacterial viruses. J Bacteriol 1953, 65:113-121.

17. Luria $\mathrm{SE}$, Human ML: A nonhereditary, host-induced variation of bacterial viruses. J Bacteriol 1952, 64:557-569.

18. Roberts RJ, Vincze T, Posfai J, Macelis D: REBASE-a database for DNA restriction and modification: enzymes, genes and genomes. Nucleic Acids Res 2010, 38:D234-236

19. Roberts RJ, Belfort M, Bestor T, Bhagwat AS, Bickle TA, Bitinaite J, Blumenthal RM, Degtyarev S, Dryden DT, Dybvig K, et al: A nomenclature for restriction enzymes, DNA methyltransferases, homing endonucleases and their genes. Nucleic Acids Res 2003, 31:1805-1812.

20. Arber W, Linn S: DNA modification and restriction. Annu Rev Biochem 1969, 38:467-500.

21. Murray NE: 2001 Fred Griffith review lecture. Immigration control of DNA in bacteria: self versus non-self. Microbiology 2002, 148:3-20.

22. Thomas CM, Nielsen KM: Mechanisms of, and barriers to, horizontal gene transfer between bacteria. Nat Rev Microbiol 2005, 3:711-721. 
23. Ohshima H, Matsuoka S, Asai K, Sadaie Y: Molecular organization of intrinsic restriction and modification genes BsuM of Bacillus subtilis Marburg. J Bacterio/ 2002, 184:381-389.

24. Iwai M, Katoh H, Katayama M, Ikeuchi M: Improved genetic transformation of the thermophilic cyanobacterium, Thermosynechococcus elongatus BP-1. Plant Cell Physiol 2004, 45:171-175.

25. Kawabata H, Norris SJ, Watanabe H: BBE02 disruption mutants of Borrelia burgdorferi B31 have a highly transformable, infectious phenotype. Infect Immun 2004, 72:7147-7154.

26. Dong H, Zhang Y, Dai Z, Li Y: Engineering clostridium strain to accept unmethylated DNA. PLoS One 2010, 5:e9038.

27. Benson DA, Karsch-Mizrachi I, Lipman DJ, Ostell J, Sayers EW: GenBank. Nucleic Acids Res 2010, 38:D46-51.

28. Bredholt S, Sonne-Hansen J, Nielsen P, Mathrani IM, Ahring BK Caldicellulosiruptor kristjanssonii sp. nov., a cellulolytic, extremely thermophilic, anaerobic bacterium. Int J Syst Bacteriol 1999, 49(3):991-996.

29. Hamilton-Brehm SD, Mosher JJ, Vishnivetskaya T, Podar M, Carroll S, Allman S, Phelps TJ, Keller M, Elkins JG: Caldicellulosiruptor obsidiansis sp. nov., an anaerobic, extremely thermophilic, cellulolytic bacterium isolated from obsidian pool, yellowstone national park. Appl Environ Microbiol 2010, 76:1014-1020.

30. Huang CY, Patel BK, Mah RA, Baresi L: Caldicellulosiruptor owensensis sp. nov., an anaerobic, extremely thermophilic, xylanolytic bacterium. Int J Syst Bacteriol 1998, 48(1):91-97.

31. Miroshnichenko ML, Kublanov IV, Kostrikina NA, Tourova TP, Kolganova TV, Birkeland NK, Bonch-Osmolovskaya EA: Caldicellulosiruptor kronotskyensis sp. nov. and Caldicellulosiruptor hydrothermalis sp. nov., two extremely thermophilic, cellulolytic, anaerobic bacteria from Kamchatka thermal springs. Int J Syst Evol Microbiol 2008, 58:1492-1496.

32. Rainey FA, Donnison AM, Janssen PH, Saul D, Rodrigo A, Bergquist PL, Daniel RM, Stackebrandt E, Morgan HW: Description of Caldicellulosiruptor saccharolyticus gen. nov., sp. nov: an obligately anaerobic, extremely thermophilic, cellulolytic bacterium. FEMS Microbiol Lett 1994, 120:263-266.

33. Svetlichnyi VA, Svetlichnaya TP, Chernykh NA, Zavarzin GA: Anaerocellum thermophilum Gen. Nov Sp. Nov. An extremely thermophilic cellulolytic eubacterium isolated from Hot-springs in the valley of geysers. Microbiology 1990, 59:598-604.

34. Grogan DW: Cytosine methylation by the Sual restriction-modification system: implications for genetic fidelity in a hyperthermophilic archaeon J Bacterio/ 2003, 185:4657-4661.

35. Donahue JP, Israel DA, Peek RM, Blaser MJ, Miller GG: Overcoming the restriction barrier to plasmid transformation of Helicobacter pylori. Mol Microbiol 2000, 37:1066-1074.

36. Chung D, Farkas J, Westpheling J: Detection of a novel active transposable element in Caldicellulosiruptor hydrothermalis and a new search for elements in this genus. J Ind Microbiol Biotechnol 2013, 40(5):517-521. doi:10.1007/s10295-013-1244-z.

37. Clausen A, Mikkelsen MJ, Schroder I, Ahring BK: Cloning, sequencing, and sequence analysis of two novel plasmids from the thermophilic anaerobic bacterium Anaerocellum thermophilum. Plasmid 2004, 52:131-138

38. Elhai J, Vepritskiy A, Muro-Pastor AM, Flores E, Wolk CP: Reduction of conjugal transfer efficiency by three restriction activities of Anabaena sp. strain PCC 7120. J Bacteriol 1997, 179:1998-2005.

39. Lee SY, Mermelstein LD, Bennett GN, Papoutsakis ET: Vector construction, transformation, and gene amplification in Clostridium acetobutylicum ATCC 824. Ann N Y Acad Sci 1992, 665:39-51.

40. Edwards RA, Helm RA, Maloy SR: Increasing DNA transfer efficiency by temporary inactivation of host restriction. Biotechniques 1999, 26:892-894. 896, 898 passim

41. van der Rest ME, Lange C, Molenaar D: A heat shock following electroporation induces highly efficient transformation of Corynebacterium glutamicum with xenogeneic plasmid DNA. Appl Microbiol Biotechnol 1999, 52:541-545.

42. Tripathi SA, Olson DG, Argyros DA, Miller BB, Barrett TF, Murphy DM, McCool JD, Warner AK, Rajgarhia VB, Lynd LR, et al: Development of pyrF-based genetic system for targeted gene deletion in Clostridium thermocellum and creation of a pta mutant. Appl Environ Microbiol 2010, 76:6591-6599.
43. Farkas J, Chung D, Cha M, Copeland J, Grayeski P, Westpheling J: Improved growth media and culture techniques for genetic analysis and assessment of biomass utilization by Caldicellulosiruptor bescii. $J$ Ind Microbiol Biotechnol 2013, 40:41-49. doi:10.1007/s10295-012-1202-1.

44. Sambrook J, Russell D: Molecular cloning: a laboratory manual. Cold Spring Harbor Laboratory Press; 2001.

doi:10.1186/1754-6834-6-82

Cite this article as: Chung et al:: Overcoming restriction as a barrier to DNA transformation in Caldicellulosiruptor species results in efficient marker replacement. Biotechnology for Biofuels 2013 6:82.

\section{Submit your next manuscript to BioMed Central and take full advantage of:}

- Convenient online submission

- Thorough peer review

- No space constraints or color figure charges

- Immediate publication on acceptance

- Inclusion in PubMed, CAS, Scopus and Google Scholar

- Research which is freely available for redistribution

Submit your manuscript at www.biomedcentral.com/submit
C Biomed Central 